\title{
Characterization of cottage cheese using Weissella cibaria D30: Physicochemical, antioxidant, and antilisterial properties
}

\author{
K. M. G. M. M. Kariyawasam, R. K. C. Jeewanthi, N.-K. Lee, and H.-D. Paik* \\ Department of Food Science and Biotechnology of Animal Resources, Konkuk University, Seoul 05029, Korea
}

\section{ABSTRACT}

This study aimed to evaluate the potential of Weissella cibaria D30 as an adjunct culture in cottage cheese, including an assessment of antioxidant, antilisterial, and compositional parameters. Cottage cheese samples were manufactured using a commercial starter culture and probiotic strains Lactobacillus rhamnosus GG (GG) or W. cibaria D30 (W) and without probiotic (control). Samples were stored at $4 \pm 1^{\circ} \mathrm{C}$ for $28 \mathrm{~d}$. Bacterial cell counts (log cfu/g) of control, GG, and W samples were counted at $0,7,14,21$, and 28 d. Counts of $W$. cibaria D30 in the $\mathrm{W}$ samples remained at 6.85 $\log \mathrm{cfu} / \mathrm{g}$ after $28 \mathrm{~d}$. Total solids, fat, protein, ash, and $\mathrm{pH}$ were measured and no significant differences were observed in compositional parameters or $\mathrm{pH}$ after $28 \mathrm{~d}$ of storage in all cheeses except those inoculated to Listeria monocytogenes. To measure the antilisterial effect, Listeria monocytogenes was inoculated into the cottage cheese samples and bacterial cell counts were obtained at $0,6,12,24,48,72,96,120$, and 144 h. Listeria monocytogenes counts were less than the analytical limit of detection $(<10 \mathrm{cfu} / \mathrm{g})$ in the inoculated $\mathrm{GG}$ and $\mathrm{W}$ samples, whereas the counts of L. monocytogenes in the inoculated control sample remained at 3.0 $\log \mathrm{cfu} / \mathrm{g}$ after $144 \mathrm{~h}$. We used the DPPH (2,2-diphenyl1-picrylhydrazyl) and ABTS [2,2'-azino-bis(3-ethylbenzothiazoline-6-sulfonic acid)] radical scavenging activity assays to assess antioxidant activity: GG and W samples exhibited significant increases in antioxidant activity compared with the control sample. These results indicate that $W$. cibaria D30 has potential as an adjunct culture in the dairy industry.

Key words: probiotic, cottage cheese, antioxidant, antilisterial effect

Received July 10, 2018.

Accepted January 10, 2019.

*Corresponding author: hdpaik@konkuk.ac.kr

\section{INTRODUCTION}

Probiotics are defined as "live microorganisms which when administered in adequate numbers confer a health benefit to the host" (FAO/WHO, 2001). Although probiotics must be able to survive adequately in food carriers, their viability after passing through the gastrointestinal tract is also crucial. Various dairy products have been investigated for their effect on probiotic viability after exposure to the gastrointestinal tract, and cheese has been identified as a good carrier of probiotics (Karimi et al., 2011). In this regard, cheese has certain beneficial characteristics, including physical and chemical properties. High fat content, high water activity, and the $\mathrm{pH}$ of cheese may offer added protection to probiotics and help them maintain higher viability throughout gastric transit (Phillips et al., 2006; Makelainen et al., 2009). Furthermore, cheese has a higher buffering capacity, which controls the high acidic environment of the gastrointestinal tract and helps to create a favorable environment for probiotic viability (Karimi et al., 2011).

Fresh cheeses are particularly vulnerable to contamination by foodborne pathogens such as Listeria monocytogenes, which is considered a postprocessing contaminant. This bacterium is usually associated with refrigerated, ready-to-eat (RTE) foods and can grow within wide temperature $\left(0\right.$ to $\left.42^{\circ} \mathrm{C}\right)$ and $\mathrm{pH}$ (4 to 9$)$ ranges and under high salt concentrations (10\%; Miyasaki et al., 2009). Listeria monocytogenes is frequently associated with listeriosis outbreaks; thus, the European Union has stipulated microbial criteria for RTE foods (EC regulation 2073), stating that in those foods "able to support the growth of L. monocytogenes," the pathogen must be absent in $25 \mathrm{~g}$ of product during their shelf life (European Commission, 2005). Hence, control of L. monocytogenes growth and multiplication in fresh cheese has been demanded. Some studies have focused on the addition of adjunct cultures isolated from herbs, fruits, and vegetables to prevent the growth of L. monocytogenes in cheese (Ho et al., 2018).

Korean kimchi is emblematic of Korean culture and is a famous side dish popular in Korea; it is made of salt- 
ed cabbage with a variety of seasonings. Many studies have generated plausible evidence of the antimicrobial, anti-inflammatory, and antiadhesive activity against foodborne pathogens and the antioxidant and anticancer effects of probiotics isolated from Korean kimchi (Lee et al., 2015; Khan and Kang, 2016; Son et al., 2017). Weissella species are reported to be prominent during kimchi fermentation and have antioxidative, antifungal, antibacterial, anticancer, anti-inflammatory, and immune-boosting potential (Kang et al., 2016). Lactic acid bacteria (LAB) isolated from fermented foods are generally recognized as safe; thus, extensive investigations have been carried out to use these novel strains as adjunct cultures in the cheese industry (Ho et al., 2018; Papadopoulou et al., 2018). Therefore, the aim of the present study was to investigate the potential of $W$. cibaria D30, isolated from Korean kimchi, as an adjunct culture in cottage cheese and to examine its characteristics with respect to physicochemical properties, antioxidant activity, and antilisterial activity in cheese.

\section{MATERIALS AND METHODS}

\section{Microorganisms and Culture Conditions}

Lactobacillus rhamnosus GG (KCTC 12202 BP) and $W$. cibaria D30 were used as probiotic strains in the present study. The $W$. cibaria D30 strain was isolated from Korean kimchi and has demonstrated probiotic characteristics (Yu et al., 2018). The cheese starter culture was supplied by Culture Systems Inc. (Mishawaka, IN) in freeze-dried form and comprised Lactobacillus acidophilus, Bifidobacterium longum, and Streptococcus thermophilus. The probiotic strains were streaked onto de Man, Rogosa, and Sharpe (MRS; BD BBL, Franklin Lakes, NJ) agar plates directly from the $-80^{\circ} \mathrm{C}$ stock and incubated at $37^{\circ} \mathrm{C}$ for $24 \mathrm{~h}$. One colony from each strain was inoculated into $10 \mathrm{~mL}$ of MRS broth and incubated under the same conditions as above. Subsequently, a $5-\mathrm{mL}$ aliquot was inoculated into $500 \mathrm{~mL}$ of MRS broth and incubated in a shaking incubator at $37^{\circ} \mathrm{C}$ and $150 \mathrm{rpm}$ for 10 to $12 \mathrm{~h}$, followed by centrifugation at $5,000 \times g$ for $10 \mathrm{~min}$ at $4^{\circ} \mathrm{C}$. The supernatant was decanted and the pellet was resuspended in low-fat milk. The colony count of the inoculum was determined by spread plating on MRS agar at required dilutions, followed by incubating at $37^{\circ} \mathrm{C}$ for $72 \mathrm{~h}$.

A 3-strain mixture of $L$. monocytogenes (ATCC 15313, Scott A NADC 2045, and H7969 serotype 4b) was used to contaminate cheese samples. The $L$. monocytogenes strains were grown in $10 \mathrm{~mL}$ of tryptic soy broth (BD BBL) at $37^{\circ} \mathrm{C}$ for $24 \mathrm{~h}$. The cells were obtained by centrifugation at $5,000 \times g$ for $10 \mathrm{~min}$ at $4^{\circ} \mathrm{C}$. The supernatant was discarded and the pellet was resuspended in $0.1 \%$ peptone water. Cell suspensions of each strain were mixed in the same volume and serially diluted to achieve a count of 5 to $5.5 \mathrm{log} \mathrm{cfu} / \mathrm{g}$ in cottage cheese. The colony count of the inoculum was determined by spread plating on listeria selective agar (Oxoid Ltd., Basingstoke, UK) at required dilutions and then incubating at $37^{\circ} \mathrm{C}$ for $48 \mathrm{~h}$.

\section{Preparation of Cottage Cheese}

Commercially available pasteurized low-fat milk (4\% fat, Seoul, South Korea) was used to produce cottage cheese. Cheese was manufactured according to Jeon et al. (2016) with some modifications. The milk was preheated to $37^{\circ} \mathrm{C}$, starter culture and liquid animal rennet (Maysa, Istanbul, Turkey) were added at $0.2 \%$ (about $10^{9} \mathrm{cfu} / \mathrm{g}$ ) and $100 \mu \mathrm{L} / \mathrm{L}$, respectively. Cheese milk was incubated at $37^{\circ} \mathrm{C}$ until the $\mathrm{pH}$ reached approximately 4.7 to 4.5 . When the curd was produced, it was cut manually with aid of a cheese wire knife into $1-\mathrm{cm}^{3}$ pieces. Subsequently, the whey was removed by 2 to 3 repetitive washings with cold water $\left(4^{\circ} \mathrm{C}\right)$.

Probiotic was added at $10^{9} \mathrm{cfu} / \mathrm{g}$ after the addition of the starter culture. The control cheese sample was prepared following the same procedure without adding probiotics. For antilisterial activity, cheese samples were cut into small slices $(3 \times 6 \mathrm{~cm})$, and $100 \mu \mathrm{L}$ of inoculum was spread over cheese slices by using a bent glass rod. Inoculated individual pieces were vacuumpacked and stored at $4^{\circ} \mathrm{C}$.

Six types of cheese were prepared and labeled as follows: cheese inoculated with starter culture and $L$. rhamnosus $\mathrm{GG}$ as adjunct (GG); W = cheese inoculated with starter culture and W. cibaria D30 as adjunct (W); cheese inoculated with starter culture only (control, C); GG cheese inoculated with L. monocytogenes (GGL); W cheese inoculated with L. monocytogenes (WL); and C cheese inoculated with L. monocytogenes (CL).

\section{Composition and $\mathrm{pH}$}

Cheese samples were analyzed for protein, fat, total solids contents, and ash. Total protein and fat were analyzed by the Kjeldahl method (method 991.20; AOAC International, 2006) and Soxhlet extraction method, respectively. Total solids content was analyzed by oven drying a known weight of samples at $102^{\circ} \mathrm{C}$ for 3 to $4 \mathrm{~h}$ until at a constant weight. Ash content was obtained by heating appropriate weights of samples in a muffle furnace at $550^{\circ} \mathrm{C}$ overnight. The $\mathrm{pH}$ of all 
cottage cheese samples was measured using a digital pH meter (WTW-720, WTW, Weilheim, Germany) equipped with a glass electrode, which was immersed in cheese samples homogenized with distilled water. All analyses were conducted in triplicate.

\section{Viability and Verification of LAB}

Lactic acid bacteria counts of cheese samples were obtained at $0,7,14,21$, and $28 \mathrm{~d}$ of storage according to the method of Abadia-Garcia et al. (2013). Briefly, cheese samples $(10 \mathrm{~g})$ were homogenized in $90 \mathrm{~mL}$ of $0.1 \%$ peptone water and subsequently macerated in a stomacher for $1 \mathrm{~min}$. The LAB were enumerated by spread plating on MRS agar at required dilutions followed by incubating at $37^{\circ} \mathrm{C}$ for $72 \mathrm{~h}$. The count of $W$. cibaria D30 in the $\mathrm{W}$ sample was taken at the end of shelf life $(28 \mathrm{~d})$ and verification was done based on morphology of the strain.

\section{Antioxidant Activity}

Water-Soluble Extracts. Water-soluble extracts (WSE) were prepared using the method of Perna et al. (2015) with some modifications. Briefly, $10 \mathrm{~g}$ of cheese sample was suspended in $30 \mathrm{~mL}$ of distilled water and kept at $40^{\circ} \mathrm{C}$ under gentle stirring for approximately 1 h. The homogenates were centrifuged at $5,000 \times g$ at $4^{\circ} \mathrm{C}$ for $30 \mathrm{~min}$. Subsequently, the uppermost fat layer was removed, the supernatant was filtered through Whatman No. 2 filter paper, and the WSE were further used to analyze antioxidant activity.

Antioxidant Activity Assays. Total antioxidant activity was determined according to the method of Savikin et al. (2009). Two hundred microliters of WSE was added to $1 \mathrm{~mL}$ of freshly prepared $100 \mu M$ 2,2-diphenyl-2-picrylhydrazyl radical (DPPH) and allowed to stand in the dark for 15 to $20 \mathrm{~min}$. Absorbance was measured by spectrophotometer at $517 \mathrm{~nm}$. Three replicates were carried out for each sample. The absorbance of the blank was measured by using distilled water and following the same procedure as above. The results were expressed as percentage of scavenging activity, which was calculated as follows:

$$
\begin{gathered}
\text { DPPH radical scavenging activity }(\%)= \\
{\left[\left(\mathrm{A}_{\text {control }}-\mathrm{A}_{\text {sample }}\right) / \mathrm{A}_{\text {control }}\right] \times 100,}
\end{gathered}
$$

where $\mathrm{A}_{\text {control }}$ and $\mathrm{A}_{\text {sample }}$ represent the absorbance of control (distilled water) and WSE, respectively.

The 2,2-azinobis (3-ethylbenzothiazoline-6-sulfonic acid) di-ammonium salt (ABTS) assay was carried out as described by Re et al. (1999) with some modifications.
The ABTS radical solution was prepared by reacting 14 $\mathrm{m} M$ ABTS and $5 \mathrm{~m} M$ potassium persulfate in the dark at room temperature for 12 to $16 \mathrm{~h}$. Before the assay, the $\mathrm{ABTS}^{\bullet+}$ radical cation solution was diluted with 0.1 $M$ ethanol at a ratio of 1:10 to obtain absorbance of 0.7 \pm 0.02 at $734 \mathrm{~nm}$. Then, $20 \mu \mathrm{L}$ of sample (WSE) was suspended in $980 \mu \mathrm{L}$ of the prepared $\mathrm{ABTS}^{\bullet+}$ radical cation solution and incubated at $37^{\circ} \mathrm{C}$ for $5 \mathrm{~min}$. The absorbance was then measured at $734 \mathrm{~nm}$. This experiment was conducted in 3 replicates. The formula used to calculate the scavenging activity was as follows:

$$
\begin{gathered}
\text { ABTS radical scavenging activity }(\%)= \\
{\left[\left(\mathrm{A}_{\text {control }}-\mathrm{A}_{\text {sample }}\right) / \mathrm{A}_{\text {control }}\right] \times 100,}
\end{gathered}
$$

where $A_{\text {control }}$ and $A_{\text {sample }}$ represent the absorbance of control (distilled water) and WSE, respectively.

\section{Viability of L. monocytogenes}

The viability of $L$. monocytogenes in cheese samples was evaluated at $0,6,12,24,48,72,96,120$, and $144 \mathrm{~h}$. Enumeration was carried out according to the method of Jesus et al. (2016). Briefly, $10 \mathrm{~g}$ of cheese sample was homogenized with $90 \mathrm{~mL}$ of $0.1 \%$ sterile peptone water, followed by maceration in a stomacher for $1 \mathrm{~min}$. Decimal dilutions were spread-plated on listeria selective agar (Oxoid Ltd.) and incubated at $37^{\circ} \mathrm{C}$ for $48 \mathrm{~h}$.

\section{Statistical Analysis}

The results were obtained for each treatment in triplicate and are presented as means \pm standard deviations. Statistical analyses were conducted using IBM SPSS statistics 20 (SPSS/IBM Corp., Chicago, IL). The data were assessed using one-way ANOVA. A difference was considered significant at $P \leq 0.05$ using Duncan's multiple range test.

\section{RESULTS AND DISCUSSION}

\section{Viability of LAB in Cottage Cheese at Refrigerated Storage $\left(4^{\circ} \mathrm{C}\right)$}

The changes in microflora during $28 \mathrm{~d}$ of storage at $4^{\circ} \mathrm{C}$ are illustrated in Figure 1. On d 0, total LAB counts were $8.5 \pm 0.01,9.02 \pm 0.05$, and $8.99 \pm 0.06$ $\log \mathrm{cfu} / \mathrm{g}$ in $\mathrm{C}, \mathrm{GG}$, and $\mathrm{W}$ samples, respectively. At 7 $\mathrm{d}$ of storage, LAB count increased in all cheese samples and reached $8.76 \pm 0.04,9.34 \pm 0.05$, and $9.03 \pm 0.05$ $\log \mathrm{cfu} / \mathrm{g}$ in $\mathrm{C}, \mathrm{GG}$, and $\mathrm{W}$ samples, respectively. The LAB count continued to increase until $14 \mathrm{~d}$ of storage in the GG and W samples, whereas a significant reduc- 


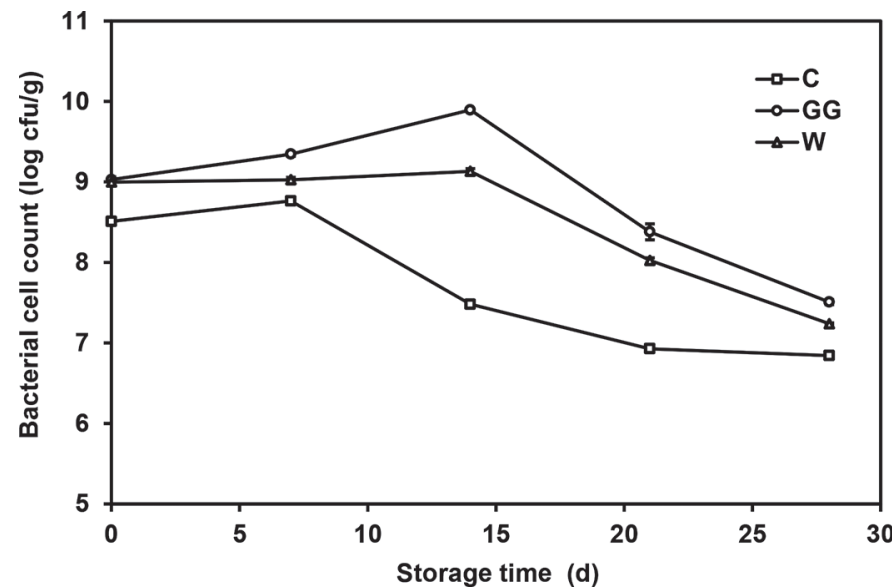

Figure 1. Bacterial cell counts of lactic acid bacteria in cottage cheese during storage at $4^{\circ} \mathrm{C}$. Results are expressed as mean $\pm \mathrm{SD}(\mathrm{n}=$ 3 ). $\mathrm{C}=$ cheese inoculated with starter culture (control); $\mathrm{GG}=$ cheese inoculated with starter culture and Lactobacillus rhamnosus GG as adjunct; $\mathrm{W}=$ cheese inoculated with starter culture and Weissella cibaria D30 as adjunct.

tion $(1.2 \log \mathrm{cfu} / \mathrm{g})$ was observed in the $\mathrm{C}$ sample $(P<$ $0.05)$. The declining $\mathrm{LAB}$ in the $\mathrm{C}$ sample after $7 \mathrm{~d}$ can be explained by the high vulnerability of starter LAB to the harsh cheese environment such as high $\mathrm{pH}(\mathrm{pH}$ $4.4-4.5)$, no residual lactose, and low temperature $\left(4^{\circ} \mathrm{C}\right.$; Steele et al., 2013). In contrast, the steady increase in LAB until $14 \mathrm{~d}$ in the GG and $\mathrm{W}$ samples can be attributed partially to high tolerance of nonstarter LAB, such as L. rhamnosus GG and W. cibaria D 30 (Lazzi et al., 2014). In particular, the survivability of L. rhamnosus GG to pyruvate degradation and ribose catabolism has been demonstrated in several cheeses (Lazzi et al., 2014), and W. cibaria D30 shows high tolerance at $\mathrm{pH}$ 3 (Yu et al., 2018).

Nonetheless, the LAB count decreased in all samples after $14 \mathrm{~d}$ of storage $(P<0.05)$. At $21 \mathrm{~d}$ of storage, LAB counts were $6.93 \pm 0.07,8.38 \pm 0.17$, and $8.03 \pm$ $0.05 \log \mathrm{cfu} / \mathrm{g}$ in the $\mathrm{C}, \mathrm{GG}$, and $\mathrm{W}$ samples, respectively. At $28 \mathrm{~d}$ of storage, LAB counts reached $6.84 \pm$
$0.05,7.51 \pm 0.053$, and $7.24 \pm 0.015 \log \mathrm{cfu} / \mathrm{g}$ in the $\mathrm{C}$, GG, and W samples, respectively. Demirci et al. (2017) showed a decline in viable count of Lactobacillus casei 431 in yogurt beyond $14 \mathrm{~d}$ of storage. This behavior could be due to the inhibitory activities of LAB, such as production of organic acids (lactic acid), hydrogen peroxide, nutrient competition, bacteriocin, diacetyl, and alcoholic compounds (Shah, 2000; Karimi et al., 2011). However, the rate of decline of viable cell count was lower in the cottage cheese samples with probiotics ( $\mathrm{GG}$ and $\mathrm{W}$ ) than in the $\mathrm{C}$ sample. In addition, we detected no difference in LAB viability in the GG and W samples $(P>0.05)$.

The general shelf life of fresh cheese stored in a refrigerator is 10 to $12 \mathrm{~d}$. Nevertheless, at the end of the study period (after $28 \mathrm{~d}$ ), the viable count of $W$. cibaria D30 in W cheese was $6.85 \mathrm{log} \mathrm{cfu} / \mathrm{g}$.

\section{Compositional Analysis and $\mathrm{pH}$}

The compositional data of all samples after $28 \mathrm{~d}$ of storage are shown in Table 1. Values of experimental cheese samples were compared with those of the control cheese. The addition of probiotics did not have a significant effect on protein, TS, or ash content. The addition of probiotics reduced the fat content of the experimental samples but not significantly $(P>0.05)$. Abadia-Garcia et al. (2013) reported the influence of Lactobacillus casei ATCC 373 and L. rhamnosus GG ATCC 53103 added to cottage cheese. We did not detect a significant difference $(P>0.05)$ between experimental samples in $\mathrm{pH}$ levels at $28 \mathrm{~d}$ of storage. The $\mathrm{pH}$ values were $4.58 \pm 0.01,4.57 \pm 0.01,4.56 \pm 0.01,4.52$ \pm 0.02 , and $4.54 \pm 0.02$ in $\mathrm{C}, \mathrm{GG}, \mathrm{W}, \mathrm{GGL}$, and $\mathrm{WL}$ samples, respectively.

\section{Antioxidant Activity of WSE During Storage Period}

The antioxidant activity of cottage cheese samples during storage at $4^{\circ} \mathrm{C}$ was analyzed at $0,7,14,21$, and

Table 1. Composition and $\mathrm{pH}$ of cottage cheese samples after $28 \mathrm{~d}$ of storage at $4^{\circ} \mathrm{C}^{1}$

\begin{tabular}{|c|c|c|c|c|c|}
\hline \multirow[b]{2}{*}{ Item } & \multicolumn{5}{|c|}{ Cottage cheese sample ${ }^{2}$} \\
\hline & $\mathrm{C}$ & GG & $\mathrm{W}$ & GGL & WL \\
\hline Total solids (\%) & $24.05 \pm 0.09^{\mathrm{a}}$ & $24.04 \pm 0.14^{\mathrm{a}}$ & $24.02 \pm 0.14^{\mathrm{a}}$ & $24.02 \pm 0.15^{\mathrm{a}}$ & $24.0 \pm 0.03^{\mathrm{a}}$ \\
\hline Protein $(\%)$ & $20.70 \pm 0.12^{\mathrm{a}}$ & $20.94 \pm 0.15^{\mathrm{a}}$ & $20.93 \pm 0.04^{\mathrm{a}}$ & $20.84 \pm 0.05^{\mathrm{a}}$ & $20.91 \pm 0.09^{\mathrm{a}}$ \\
\hline Fat $(\%)$ & $3.94 \pm 0.05^{\mathrm{a}}$ & $3.74 \pm 0.02^{\mathrm{a}}$ & $3.79 \pm 0.06^{\mathrm{a}}$ & $3.79 \pm 0.01^{\mathrm{a}}$ & $3.68 \pm 0.01^{\mathrm{a}}$ \\
\hline Ash (\%) & $1.83 \pm 0.04^{\mathrm{a}}$ & $1.84 \pm 0.02^{\mathrm{a}}$ & $1.80 \pm 0.02^{\mathrm{a}}$ & $1.79 \pm 0.02^{\mathrm{a}}$ & $1.74 \pm 0.02^{\mathrm{a}}$ \\
\hline $\mathrm{pH}$ & $4.58 \pm 0.01^{\mathrm{a}}$ & $4.57 \pm 0.02^{\mathrm{a}}$ & $4.56 \pm 0.01^{\mathrm{a}}$ & $4.52 \pm 0.02^{\mathrm{a}}$ & $4.54 \pm 0.02^{\mathrm{a}}$ \\
\hline
\end{tabular}

\footnotetext{
${ }^{a}$ Means within a row with different superscripts differ $(P<0.05)$.

${ }^{1}$ All values are means of 3 replicates $( \pm \mathrm{SD})$.

${ }^{2} \mathrm{C}=$ cheese inoculated with starter culture (control); GG = cheese inoculated with Lactobacillus rhamnosus $\mathrm{GG}$ as adjunct; $\mathrm{W}=$ cheese inocu-
} lated with Weissella cibaria D30 as adjunct; GGL and WL = GG and W cheeses inoculated with Listeria monocytogenes. 


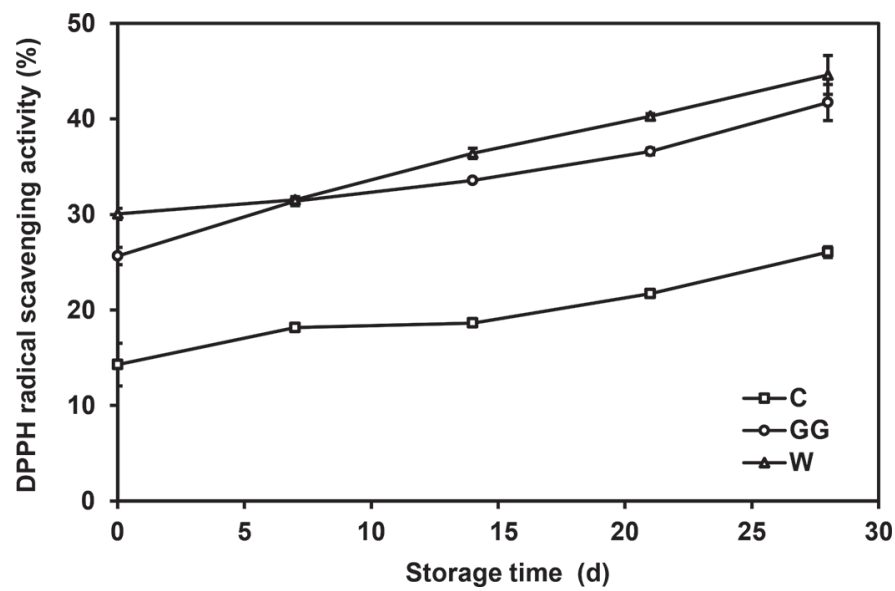

Figure 2. Antioxidant activity of water-soluble extracts (WSE) of cottage cheese samples measured by the DPPH (2,2-diphenyl-1-picrylhydrazyl) scavenging assay. Antioxidant activity is expressed as percent of scavenging activity. Results are expressed as mean $\pm \mathrm{SD}(\mathrm{n}=$ $3) . \mathrm{C}=$ cheese inoculated with starter culture (control); $\mathrm{GG}=$ cheese inoculated with starter culture and Lactobacillus rhamnosus GG as adjunct; $\mathrm{W}=$ cheese inoculated with starter culture and Weissella cibaria D30 as adjunct.

$28 \mathrm{~d}$ by using the DPPH and ABTS radical scavenging assays. Figures 2 and 3 show the antioxidant activities for the DPPH and ABTS assays, respectively.

Radical scavenging activities increased significantly $(P<0.05)$ in both assays with increased storage time. Nonetheless, the cottage cheese samples with added probiotic strains had higher scavenging activities than the control sample $(P<0.05)$. At the end of the storage period (28 d), DPPH and ABTS radical scavenging

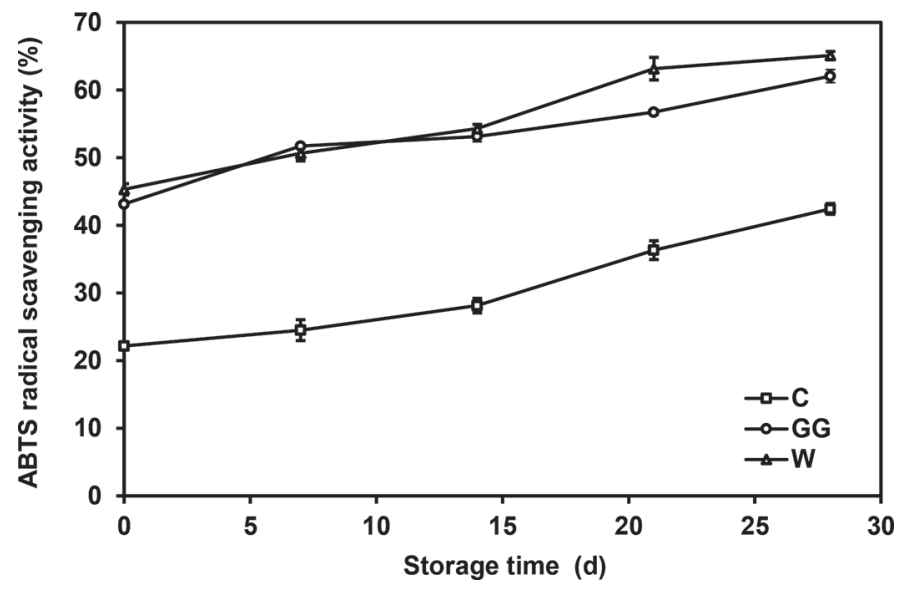

Figure 3. Antioxidant activity of water-soluble extracts (WSE) of cottage cheese obtained by the ABTS [2,2'-azino-bis(3-ethylbenzothiazoline-6-sulfonic acid)] assay. Antioxidant activity is expressed as percent of scavenging activity. Results are expressed as mean $\pm \mathrm{SD}(\mathrm{n}=$ $3) . \mathrm{C}=$ cheese inoculated with starter culture (control); $\mathrm{GG}=$ cheese inoculated with starter culture and Lactobacillus rhamnosus GG as adjunct; $\mathrm{W}=$ cheese inoculated with starter culture and Weissella cibaria D30 as adjunct. activities in $\mathrm{C}, \mathrm{GG}$, and $\mathrm{W}$ samples were, respectively, $26.04 \pm 0.98 \%, 41.71 \pm 1.02 \%$, and $44.6 \pm 0.93 \%$ in the DPPH assay, and $42.43 \pm 1.07 \%, 62.05 \pm 1.65 \%$, and $65.10 \pm 1.03 \%$ in the ABTS assay. There was no difference in antioxidant activity among cheese samples with different strains of probiotics $(P>0.05)$. These findings are in agreement with those of Mushtaq et al. (2016), who studied the antioxidant activity of Lactobacillus casei 279, Lactobacillus brevis 021, and Lactobacillus plantarum 01 strains added to Kalari cheese. This can be explained by the fact that cheese contains a high amount of protein and these proteins (especially casein) are subjected to proteolysis by enzymes present in milk, such as plasmin. In addition, the residuals of rennet added during the cheese-making process and microbial proteolytic enzymes result in the production of bioactive peptides. These bioactive peptides are responsible for antioxidant activity by inhibiting the formation of free radicals such as oxygen and nitrogen, for example, via different mechanisms (Sarmadi and Ismail, 2010). However, samples with probiotics showed an increase $(P<0.05)$ in antioxidant activities, which may be explained by the fact that some LAB have specific abilities to produce antioxidant enzymes (i.e., superoxide dismutase, catalase, glutathionine reductases, and thioredoxin) to scavenge free radicals, thereby resulting in oxidative defense (Ianniello et al., 2015). Overall, results showed that the antioxidant activity of fresh cheese was enhanced by the addition of probiotic strains.

\section{Viability and Behavior of Inoculated L. monocytogenes in Cottage Cheese During Storage}

When pasteurized milk is used for cheese manufacturing, a major cause of cheese spoilage is cross-contamination due to improper handling, which mainly affects the surface of cheese (Carminati et al., 2000; Frye and Donnelly, 2005). In this study, the surface of the cottage cheese was inoculated with a multi-strain cocktail of L. monocytogenes to simulate this postprocessing contamination. Figure 4 shows the behavior of L. monocytogenes throughout storage. The initial counts of $L$. monocytogenes were 5 to $5.5 \log \mathrm{cfu} / \mathrm{g}$ in all 3 samples (CL, GGL, and WL). We detected no significant difference in L. monocytogenes count in the control sample $(\mathrm{CL})$ at $6 \mathrm{~h}(P>0.05)$, whereas the counts of GGL and WL samples were significantly reduced by 0.87 and $0.77 \log \mathrm{cfu} / \mathrm{g}$, respectively $(P<0.05)$. Beyond 6 h, L. monocytogenes counts declined steadily in all 3 samples, and at $120 \mathrm{~h}$ the count reached $2.0 \mathrm{log} \mathrm{cfu} / \mathrm{g}$ in the GGL and WL samples and $3.4 \mathrm{log} \mathrm{cfu} / \mathrm{g}$ in the CL sample. At $144 \mathrm{~h}$, the L. monocytogenes counts in 


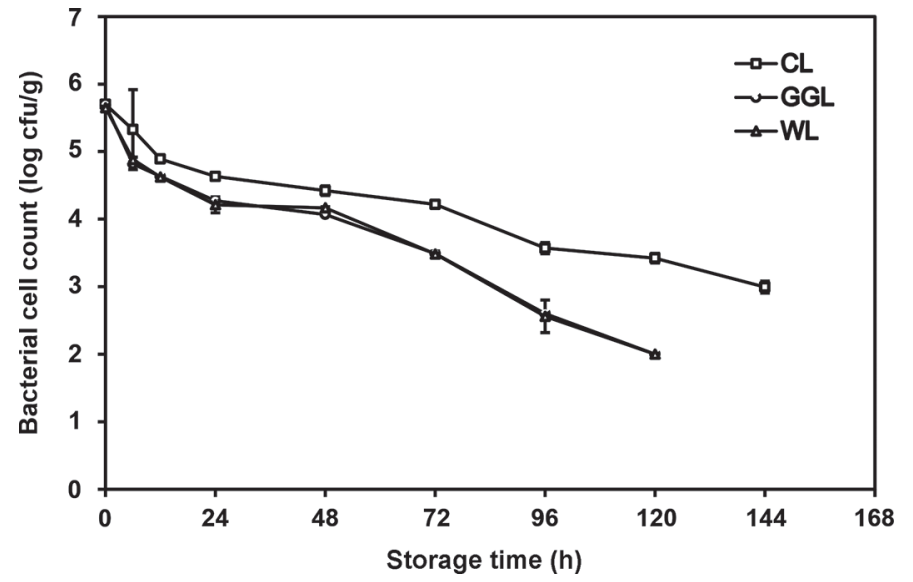

Figure 4. Bacterial cell counts of Listeria monocytogenes during storage at $4^{\circ} \mathrm{C}$. Results are expressed as mean $\pm \mathrm{SD}(\mathrm{n}=3) . \mathrm{CL}$, GGL, and $\mathrm{WL}=\mathrm{C}, \mathrm{GG}$, and $\mathrm{W}$ cheeses inoculated with $L$. monocytogenes, where $\mathrm{C}=$ cheese inoculated with starter culture (control); $\mathrm{GG}=$ cheese inoculated with starter culture and Lactobacillus rhamnosus $\mathrm{GG}$ as adjunct; $\mathrm{W}=$ cheese inoculated with starter culture and Weissella cibaria D30 as adjunct.

GGL and WL samples were below the limit of detection $(<10 \mathrm{cfu} / \mathrm{g})$, whereas that of the CL sample was 3.0 $\log \mathrm{cfu} / \mathrm{g}$.

These results demonstrated that L. monocytogenes was able to survive for a longer period in CL (15 d) than in the GGL and WL samples. These findings are in agreement with results from other studies in Galotyri cheese, a soft acid curd cheese (Rogga et al., 2005) and Greek Graviera hard cheese (Giannou et al., 2009). Rogga et al. (2005) and Giannou et al. (2009) explained that the combined hurdle effect of lactic acid, $\mathrm{pH}$, and water activity inhibited the growth of the pathogen but that it survived for a longer period with a low death rate under refrigerated storage. Thus, faster inhibition $(144 \mathrm{~h})$ of L. monocytogenes in the GGL and WL samples demonstrated that L. rhamnosus GG and $W$. cibaria D30 act as protective adjunct cultures through the potential formation of antimicrobial compounds such as acetic acid, lactic acid, and bacteriocin.

\section{CONCLUSIONS}

The present study revealed that the $W$. cibaria $\mathrm{D} 30$ strain isolated from Korean kimchi has potential for use as an adjunct culture in cheese manufacture. In particular, W. cibaria D 30 could provide additional hurdle effects to prevent the growth of L. monocytogenes and ensure the microbial safety of RTE soft cheeses. Ascertaining the long-term survival of $L$. monocytogenes in RTE soft cheese is crucial because of the potential risk of transmittance of the pathogen from cheese slicers to other RTE foods that might support its growth. In ad- dition, the use of $W$. cibaria D 30 enhanced antioxidant activity and did not affect the compositional parameters or $\mathrm{pH}$, which ensures its potential use as an adjunct culture in cottage cheese production to improve quality. The viability of $W$. cibaria $\mathrm{D} 30$ above the minimum threshold level of $10^{6} \mathrm{cfu} / \mathrm{g}$ until the end of the shelf life shows its potential to deliver probiotic health benefits to the consumer at the time of consumption.

\section{ACKNOWLEDGMENTS}

This paper was supported by Konkuk University (Seoul, Korea) in 2016.

\section{REFERENCES}

Abadia-Garcia, L., A. Cardador, S. T. M. del Campo, S. Arvizu, E. C. Tostado, C. R. Gonzalez, B. G. Almendarez, and S. L. A. Liano. 2013. Influence of probiotic strains added to cottage cheese on generation of potentially antioxidant peptides, anti-listerial activity, and survival of probiotic microorganisms in simulated gastrointestinal conditions. Int. Dairy J. 33:191-197.

AOAC International. 2006. Official Methods of Analysis. 18th ed. AOAC International, Washington, DC.

Carminati, D., A. Perrone, E. Neviani, and G. Mucchetti. 2000. Influence of traditional brine washing of smear Taleggio cheese on the surface spreading of Listeria innocua. J. Food Prot. 63:1353-1358.

Demirci, T., K. Aktas, D. Sozeri, H. I. Ozturk, and N. Akın. 2017. Rice bran improve probiotic viability in yoghurt and provide added antioxidative benefits. J. Funct. Foods 36:396-403.

European Commission. 2005. Commission Regulation 2073/2005/EC of 15 November 2005 on microbiological criteria for foodstuffs. Off. J. Eur. Commun. L 338:1-26.

FAO/WHO. 2001. Report on joint FAO/WHO expert consultation on evaluation of health and nutritional properties of probiotics in food including powder milk with live lactic acid bacteria. Food and Agriculture Organization of the United Nations, Rome, Italy; World Health Organization, Geneva, Switzerland.

Frye, C., and C. W. Donnelly. 2005. Comprehensive survey of pasteurized fluid milk produced in the United States reveals a low prevalence of Listeria monocytogenes. J. Food Prot. 68:973-979.

Giannou, E., A. Kakouri, B. B. Matijasic, I. Rogelj, and J. Samelis. 2009. Fate of Listeria monocytogenes on fully ripened Greek Graviera cheese stored at 4,12 , or $25^{\circ} \mathrm{C}$ in air or vacuum packages: In situ PCR detection of a cocktail of bacteriocins potentially contributing to pathogen inhibition. J. Food Prot. 72:531-538.

Ho, V. T. T., R. Lo, N. Bansal, and M. S. Turner. 2018. Characterization of Lactococcus lactis isolates from herbs, fruits and vegetables for use as bio preservatives against Listeria monocytogenes in cheese. Food Control 85:472-483.

Ianniello, R. G., A. Ricciardi, E. Parente, A. Tramutola, A. Reale, and T. Zotta. 2015. Aeration and supplementation with heme and menaquinone affect survival to stresses and antioxidant capability of Lactobacillus casei strains. Lebensm. Wiss. Technol. 60:817-824.

Jeon, E. B., S. H. Son, R. K. C. Jeewanthi, N. K. Lee, and H. D. Paik. 2016. Characterization of Lactobacillus plantarum Lb41, an isolate from kimchi and its application as a probiotic in cottage cheese. Food Sci. Biotechnol. 25:1129-1133.

Jesus, A. L. T., M. S. Fernandes, B. A. Kamimura, L. P. Silva, R. Silva, E. A. Esmerino, A. G. Cruz, and S. Sant'Ana. 2016. Growth potential of Listeria monocytogenes in probiotic cottage cheese formulations with reduced sodium content. Food Res. Int. 81:180-187.

Kang, B. K., M. S. Cho, and D. S. Park. 2016. Red pepper powder is a crucial factor that influences the ontogeny of Weissella cibaria during kimchi fermentation. Sci. Rep. 6:28232. 
Karimi, R., A. M. Mortazavian, and A. da Cruz. 2011. Viability of probiotic microorganism in cheese during production and storage: a review. Dairy Sci. Technol. 91:283-308.

Khan, I., and S. C. Kang. 2016. Probiotic potential of nutritionally improved Lactobacillus plantarum DGK-17 isolated from kimchi-A traditional Korean fermented food. Food Control 60:88-94.

Lazzi, C., S. Turroni, A. Mancini, E. Sgarbi, E. Neviani, P. Brigidi, and M. Gatti. 2014. Transcriptomic clues to understand the growth of Lactobacillus rhamnosus in cheese. BMC Microbiol. 14:28.

Lee, N. K., K. J. Han, S. H. Son, S. J. Eom, S. K. Lee, and H. D. Paik. 2015. Multifunctional effect of probiotic Lactococcus lactis KC24 isolated from kimchi. Lebensm. Wiss. Technol. 64:1036-1041.

Makelainen, H., S. Forssten, K. Ollia, L. Granlund, N. Rautonen, and A. C. Ouwehand. 2009. Probiotic lactobacilli in a semi-soft cheese survive in the simulated human gastrointestinal tract. Int. Dairy J. 19:675-683.

Miyasaki, K. N., E. Chiarini, A. S. Sant'Ana, M. T. Destro, M. Landgraf, and B. D. G. M. Franco. 2009. High prevalence, low counts and uncommon serotypes of Listeria monocytogenes in linguiça, a Brazilian fresh pork sausage. Meat Sci. 83:523-527.

Mushtaq, M., A. Gani, F. A. Masoodi, and M. Ahmad. 2016. Himalayan cheese (Kalari/Kardi) - Effect of different probiotic strains on oxidative stability, microbiological, sensory and nutraceutical properties during storage. Lebensm. Wiss. Technol. 67:74-81.

Papadopoulou, O. S., A. A. Argyri, E. E. Varzakis, C. C. Tassou, and N. G. Chorianopoulos. 2018. Greek functional Feta cheese: Enhancing quality and safety using a Lactobacillus plantarum strain with probiotic potential. Food Microbiol. 74:21-33.

Perna, A., I. Intaglietta, A. Simonetti, and E. Gambacorta. 2015. Effect of genetic type on antioxidant activity of Caciocavallo cheese during ripening. J. Dairy Sci. 98:3690-3694.

Phillips, M., K. Kailasapathy, and L. Tran. 2006. Viability of commercial probiotic cultures (L. acidophilus, Bifidobacterium sp., L. casei, L. paracasei and L. rhamnosus) in cheddar cheese. Int. J. Food Microbiol. 108:276-280.

Re, R., N. Pellegrini, A. Proteggente, A. Panala, M. Yang, and C. Rice-Evans. 1999. Antioxidant activity applying and improved ABTS radical cation decolorization assay. Free Radic. Biol. Med. 26:1231-1237.

Rogga, K. J., J. Samelis, A. Kakouri, M. C. Katsiari, I. N. Savvaidis, and M. G. Kontominas. 2005. Survival of Listeria monocytogenes in Galotyri, a traditional Greek soft acid-curd cheese, stored aerobically at $4^{\circ} \mathrm{C}$ and $12^{\circ} \mathrm{C}$. Int. Dairy J. 15:59-67.

Sarmadi, B. H., and A. Ismail. 2010. Antioxidative peptides from food proteins: A review. Peptides 31:1949-1956.

Savikin, K., G. Zdunic, T. Jankovic, T. Stanojkovic, Z. Juranic, and N. Menkovic. 2009. In vitro cytotoxic and antioxidative activity of Cornus mas and Cotinus coggygria. Nat. Prod. Res. 23:17311739.

Shah, N. P. 2000. Probiotic bacteria: Selective enumeration and survival in dairy foods. J. Dairy Sci. 83:894-907.

Son, S. H., H. L. Jeon, E. B. Jeon, N. K. Lee, Y. S. Park, D. K. Kang, and H. D. Paik. 2017. Potential probiotic Lactobacillus plantarum Ln4 from kimchi: Evaluation of $\beta$-galactosidase and antioxidant activities. Lebensm. Wiss. Technol. 85:181-186.

Steele, J., J. Broadbent, and J. Kok. 2013. Perspectives on the contribution of lactic acid bacteria to cheese flavor development. Curr. Opin. Biotechnol. 24:135-141.

Yu, H. S., N. K. Lee, Y. J. Song, S. M. Baek, A. J. Choi, C. H. Bae, and H. D. Paik. 2018. Antimicrobial and anti-adhesion activity of Weissella cibaria JW15 against foodborne pathogens. Page 56 in Proc. 5th Annu. Mtg. Int. Symp., Korea. Yeosu Expo Convention Center, The Korea Society for Microbiology and Biotechnology. 